\title{
The rs1126616 Single Nucleotide Polymorphism of the Osteopontin Gene Is Independently Associated with Cardiovascular Events in a Chronic Kidney Disease Cohort
}

\author{
Serafí Cambray ${ }^{1,+}{ }^{,}$Rajesh Kumar Galimudi ${ }^{1,+}{ }^{\dagger}$, Milica Bozic ${ }^{1,+}$, Marcelino Bermúdez-López ${ }^{1, \dagger}$,

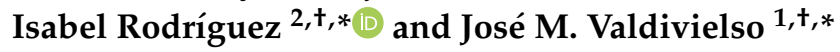 \\ 1 Vascular and Renal Translational Research Group, Biomedical Research Institute, IRBLLEIDA, \\ and RedinRen-ISCIII, 25198 Lleida, Spain; seracc@yahoo.es (S.C.); rajeshgkumar26@gmail.com (R.K.G.); \\ bozicm@medicina.udl.cat (M.B.); mbermudez@irblleida.cat (M.B.-L.) \\ 2 Bone and Mineral Research Unit, RedinRen-ISCIII, Hospital Universitario Central de Asturias, Universidad \\ de Oviedo, Instituto de Investigación Sanitaria del Principado de Asturias (ISPA), 33011 Oviedo, Spain \\ * Correspondence: isabelrodriguez2710@gmail.com (I.R.); valdivielso@irblleida.cat (J.M.V.) \\ + These authors on behalf of the NEFRONA investigators.
}

Received: 3 April 2019; Accepted: 25 April 2019; Published: 29 April 2019

check for updates

\begin{abstract}
Chronic kidney disease (CKD) is associated with a higher risk of cardiovascular events (CVE), partly due to the higher burden of atherosclerosis. Circulating Osteopontin (OPN) levels have been also shown to have a potential role in the development of atherosclerosis. Indeed, CKD patients show an increase in circulating OPN levels, but their effect of CKD-related atherosclerosis is not clear. Polymorphisms in the OPN gene (SPP1) have been studied in atheromatous disease, but reported results show conflictive findings. Thus, the main aim of the present study is to analyze the influence of SPP1 polymorphisms in CVE in CKD patients, taking into account circulating OPN levels. We followed 559 healthy controls and 2445 CKD patients without previous CVE from the National Observatory of Atherosclerosis in Nephrology study (NEFRONA study). After 48 months of follow-up 206 CVE were recorded. Genotyping for rs9138, rs1126616, rs1126772, rs11730582 and rs28357094 polymorphisms of the SPP1 gene was performed along with the measurements of plasma OPN levels. The group of patients with CVE showed higher incidence of atherosclerotic plaque $(90.3 \%$ vs $64.5 \% ; p<0.001)$ and higher OPN levels $(p<0.001)$ at baseline. Patients with the heterozygous genotype of the rs1126616 polymorphism showed a higher hazard ratio of having a CVE, even after adjustment for multiple potential confounders. After adjustment, OPN levels were no longer associated with the incidence of CVE. We found that the rs1126616 single nucleotide polymorphism (SNP) of the SPP1 gene is independently associated with a higher incidence of CVE in a cohort of CKD patients and that it could be used to predict CVE risk.
\end{abstract}

Keywords: atherosclerotic plaque; cardiovascular event; chronic kidney disease; Osteopontin; polymorphisms; Osteopontin gene (SPP1)

\section{Introduction}

Chronic kidney disease (CKD) is associated with a higher risk for cardiovascular events (CVE) [1]. This increased risk seems to be strongly associated with electrolyte disturbances in dialysis patients, with a higher burden of atheromatous plaque playing a paramount role in the earlier stages $[2,3]$. In agreement with this hypothesis, atherosclerosis associated biomarkers showed good prognostic capacity to predict CVE in CKD patients [4], and the combination of some biomarkers associated with 
the presence of atheromatous plaque like Osteoprotegerin (OPG), Osteopontin (OPN) and soluble tumor necrosis factor-like weak inducer of apoptosis (sTWEAK) increased the accuracy of predictive models for cardiovascular outcomes in CKD patients [5].

OPN is an extracellular matrix glycoprotein produced by cells involved in bone morphogenesis, which plays a major role in the control of biomineralization and calcification. OPN is a secreted protein that contains several functional domains, including a number of integrin-interacting domains which facilitate the recruitment of inflammatory cells [6]. It is upregulated in atherosclerotic settings, where it is expressed by macrophages, endothelial and vascular smooth muscle cells, and modulates the inflammatory response by recruiting multiple inflammatory cell types [7-9]. Mice overexpressing OPN show smooth muscle cell hyperproliferation, medial thickening, and neointimal formation [10], and mice with OPN deficiency display attenuated atherosclerosis [11]. In clinical studies, increased plasma OPN expression levels are associated with the presence and severity of coronary artery disease $[12,13]$ and with the levels of calcification [12,14]. Furthermore, the levels of OPN are also affecting the degree of neointima formation and of restenosis after revascularization, both in humans and in animal studies $[10,15,16]$. Finally, several studies have related high circulating levels of OPN to adverse cardiovascular events in the general population [17] and in CKD patients [18].

Apart from plasma OPN levels, single nucleotide polymorphisms (SNPs) on the SPP1 gene (the gene encoding OPN), have also been associated with atheromatous disease and cardiovascular events [19]. For instance, rs28357094 located at the SPP1 promoter has been shown to be related with increased carotid intima media thickness (cIMT) [20,21]. A second SNP, rs11730582 has also been associated with increased cIMT in stroke patients [21]. However, these results are questioned, as some researchers found no association between these polymorphisms and atherosclerotic markers [22,23]. Furthermore, most of the studies focusing in SPP1 SNPs do not quantify plasma OPN, precluding further analysis on its effects on OPN levels.

In view of these data, we studied the association of SNPs in the SPP1 gene and circulating levels of OPN with the incidence of CVE in a cohort of CKD patients during a 48 month period.

\section{Experimental Section}

\subsection{Study Design and Participants}

The NEFRONA (Observatory of Atherosclerosis in Nephrology) project is an observational, multi-center, prospective study that, from 2010 to 2012, recruited 2445 CKD patients from all over Spain $[24,25]$. Inclusion criteria were to present CKD stage 3 or higher (including patients in dialysis) and absence of any previous cardiovascular disease; CKD stage 3 was defined as glomerular filtration rate $<60 \mathrm{~mL} / \mathrm{min} / 1.73 \mathrm{~m}^{2}$ according to the 4 -variable Modification of Diet in Renal Disease (MDRD) equation [26,27]. Exclusion criteria were life expectancy below 1 year, previous carotid surgery, acquired immune deficiency syndrome infection, having any organ transplant, any infection or hospital admission during the month previous to be included and pregnancy. We also included 559 controls (MDRD above $60 \mathrm{~mL} / \mathrm{min} / 1.73 \mathrm{~m}^{2}$ ) matched by age and sex randomly recruited from several Spanish Primary Care centers during the same period (2010 to 2012).

On the inclusion day, we obtained anthropometric, demographic, and biochemical data together with a comprehensive vascular ultrasound analysis to assess the presence of atherosclerotic plaque [28].

Volunteers underwent a minimum of 4 years of follow-up and CVE events (fatal and non-fatal) were recorded by the referring physician. CVE included unstable angina, myocardial infarction, transient ischemic attack, cerebrovascular accident, congestive heart failure, arrhythmia, peripheral artery disease, amputation due to vascular disease, aortic aneurysm, myocardial infarction, arrhythmia, congestive heart failure, stroke, mesenteric infarction, and sudden death. All patients were clearly informed, and signed an informed consent; the local Ethics Committee of each hospital approved the protocol. 


\subsection{SNP Genotyping}

DNA was obtained from blood samples stored at the Biobank of the Spanish Renal Research Network (REDinREN) [29] using the QIAamp DNA Blood Kit and following manufacturer instructions. Genotyping was performed with matrix assisted laser desorption ionization time-of-flight mass spectrometry in the Sequenom MassARRAY platform ${ }^{\circledR}$, in Centro de Genotipado-Plataforma de Recursos Biomoleculares y Bioinformáticos (CEGEN-PRB2) del Instituto de Salud Carlos III (Nodo de la Universidad de Santiago de Compostela, A Coruña, Spain). As a quality control, we eliminated SNP clusters or samples with low genotyping percentage and SNPs not meeting the Hardy-Weinberg Equilibrium (HWE). We included replicates of samples between plates and samples from the Coriell Institute Biorepository for genotyping quality assessment. For this study, we focused on five SNPs distributed along the SPP1 gene in the $5^{\prime}$ upstream region (rs11730582 and rs28357094), the coding region (rs1126616) and the $3^{\prime}$ untranslated region (rs9138 and rs1126772).

\subsection{Determination of OPN Levels}

OPN serum levels were measured using MILLIPLEX ${ }^{\circledR}$ MAP kits (EMD Millipore Corporation, Darmstadt, Germany) in a blinded manner. Minimum detectable levels were $37.7 \mathrm{pg} / \mathrm{mL}$, intra-assay coefficient of variation $2 \%$, and inter-assay coefficient of variation $12 \%$.

\subsection{Statistical Analysis}

Qualitative variables were expressed as $n(\%)$, and quantitative variables as median (Q1;Q3) or mean (SD) depending on normality of distribution. Comparisons between groups were performed with Mann-Whitney U test or Student's $t$ test for non-normally or normally distributed quantitative variables, respectively, and Chi-squared test for categorical data.

To determine the genotypic association, genotype frequency, single SNP frequency under multiple inheritance models, haplotype frequency, and haplotype association with the response we used SNPStats [30]. Linkage disequilibrium (LD) was calculated with HAPLOVIEW [31] and compared to IBS population (Iberian Population in Spain) from Ensembl [32].

Kaplan-Meier curves were used to assess time to outcome according to a multiple markers score, and compared with the Mantel-Cox test. Time to event analysis was done using the Cox proportional hazards model, including adjustment for potential confounding factors. Final model was obtained through a forward stepwise method based on the likelihood ratio test. Data were presented as hazard ratios (HRs) and 95\% confidence intervals (95\% CIs), and $p$ value $<0.05$ was considered statistically significant.

\section{Results}

In the median follow-up period of 48.1 months, 206 CVE were reported (7.3\%). The group of patients suffering a CVE were older, predominantly males, with a higher body mass index, systolic blood pressure and urine albumin to creatinine ratio, and showed an increased proportion of other classical cardiovascular risk factors (smoking, diabetes, hypertension, and dyslipemia). The group of patients suffering a CVE also displayed a higher percentage of patients in a more advanced CKD stage and with atheromatous plaque. Furthermore, they had lower levels of total, low-density lipoprotein (LDL) and high-density lipoprotein (HDL) cholesterol and higher triglycerides. In addition, blood levels of phosphorus, potassium, and ultra-sensitive c-reactive protein usCRP were higher whereas levels of $25(\mathrm{OH})$ vitamin D were lower. Levels of OPN were also significantly higher in the group of patients suffering a CVE (Table 1). 
Table 1. Epidemiological, clinical, and biochemical parameters of patients according to the presence or absence of cardiovascular events.

\begin{tabular}{|c|c|c|c|c|}
\hline \multirow{2}{*}{\multicolumn{2}{|c|}{ Variable }} & No CVE & CVE & \multirow{2}{*}{$p$ Value } \\
\hline & & $n=2609$ & $n=206$ & \\
\hline \multicolumn{2}{|c|}{ Age (years) } & $59(48 ; 67)$ & $64.5(58 ; 70)$ & $<0.001$ \\
\hline \multicolumn{2}{|c|}{ Sex (Female) } & $1056(40.4)$ & $60(29)$ & 0.001 \\
\hline \multicolumn{2}{|c|}{ Body mass index $\left(\mathrm{kg} / \mathrm{m}^{2}\right)$} & $27.6(24.6 ; 31)$ & $28.9(25.7 ; 32.12)$ & 0.005 \\
\hline \multicolumn{2}{|c|}{ Smoking (Yes) } & $1481(56.7)$ & $137(66.5)$ & 0.006 \\
\hline \multicolumn{2}{|c|}{ Diabetes (Yes) } & $546(20.9)$ & $88(42.7)$ & $<0.001$ \\
\hline \multicolumn{2}{|c|}{ Hypertension (Yes) } & $2068(79.2)$ & $191(92.7)$ & $<0.001$ \\
\hline \multicolumn{2}{|c|}{ Dyslipemia (Yes) } & $1551(59.4)$ & $149(72.3)$ & $<0.001$ \\
\hline \multicolumn{2}{|c|}{ Systolic blood pressure (mmHg) } & $140(21.3)$ & $148(24.7)$ & $<0.001$ \\
\hline \multicolumn{2}{|c|}{ Dyastolic blood pressure (mmHg) } & $81(11)$ & $81(13)$ & 0.556 \\
\hline \multirow{4}{*}{$\begin{array}{l}\text { Chronic kidney } \\
\text { disease Stage }\end{array}$} & Control & $536(20.5)$ & $13(6.3)$ & \multirow{4}{*}{$<0.001$} \\
\hline & Stage 3 & $819(31.4)$ & $66(32)$ & \\
\hline & Stage $4-5$ & $684(26.2)$ & $62(30.1)$ & \\
\hline & Dialysis & $570(21.8)$ & $65(31.6)$ & \\
\hline \multicolumn{2}{|c|}{ Presence of plaque at baseline } & $1684(64.5)$ & $186(90.3)$ & $<0.001$ \\
\hline \multicolumn{2}{|c|}{ Total Cholesterol (mg/dL) } & $182(156.5 ; 208)$ & $171(141.2 ; 207)$ & 0.017 \\
\hline \multicolumn{2}{|c|}{ HDL Cholesterol (mg/dL) } & $48(39 ; 59]$ & $44(35 ; 52)$ & $<0.001$ \\
\hline \multicolumn{2}{|c|}{ LDL Cholesterol (mg/dL) } & $105(83 ; 128)$ & $98(72 ; 128)$ & 0.042 \\
\hline \multicolumn{2}{|c|}{ Triglycerides (mg/dL) } & $118(86.2 ; 166)$ & $138(100 ; 181)$ & $<0.001$ \\
\hline \multicolumn{2}{|c|}{ Glucose $(\mathrm{mg} / \mathrm{dL})$} & $96(87 ; 110)$ & $105(91.6 ; 139.2)$ & $<0.001$ \\
\hline \multicolumn{2}{|c|}{ Calcium (mg/dL) } & $9.3(8.8 ; 9.5)$ & $9.3(8.9 ; 9.7)$ & 0.095 \\
\hline \multicolumn{2}{|c|}{ Phosphate (mg/dL) } & $3.8(3.3 ; 4.4)$ & $4(3.4 ; 5)$ & 0.003 \\
\hline \multicolumn{2}{|c|}{ Sodium (mEq/L) } & $140.6(139 ; 142)$ & $140(138 ; 142)$ & 0.015 \\
\hline \multicolumn{2}{|c|}{ Potassium $(\mathrm{mEq} / \mathrm{L})$} & $4.7(4.37 ; 5.1)$ & $4.9(4.4 ; 5.3)$ & $<0.001$ \\
\hline \multicolumn{2}{|c|}{ C-reactive protein $(\mathrm{mg} / \mathrm{L})$} & $4.2(8.2)$ & $6.2(12)$ & 0.001 \\
\hline \multirow{3}{*}{ ACR (mgAlb/gCreat) } & $\mathrm{ACR}<30$ & $398(34.3)$ & $20(22.2)$ & \multirow{3}{*}{0.02} \\
\hline & $\mathrm{ACR}=30-300$ & $416(35.9)$ & $32(35.6)$ & \\
\hline & ACR $>300$ & $346(29.8)$ & $38(42.2)$ & \\
\hline \multicolumn{2}{|c|}{$25(\mathrm{OH})$ vitamin $\mathrm{D}(\mathrm{ng} / \mathrm{mL})$} & $17.1(7.8)$ & $14.6(6.9)$ & $<0.001$ \\
\hline \multicolumn{2}{|c|}{$\mathrm{OPN}(\mathrm{ng} / \mathrm{mL})$} & $16.7(9.3 ; 33)$ & $22.6(11.9 ; 53.3)$ & $<0.001$ \\
\hline
\end{tabular}

Qualitative variables are expressed as $n(\%)$ and quantitative variables as median (Q1;Q3) or mean (SD) depending on the normality of the distribution. Comparisons between groups performed with Mann-Whitney U test or Student's $t$ test for quantitative non-normally distributed variables and normally distributed respectively, and Chi-squared test for categorical data. CVE, cardiovascular events; HDL, high-density lipoprotein; LDL, low-density lipoprotein; $\mathrm{ACR}$, urine albumin to creatinine ratio; OPN, Osteopontin.

All the SNPs followed the HWE (Supplemental Table S1). We analyzed the crude association of the five SNPs (rs9138, rs1126616, rs1126772, rs11730582 and rs28357094) with CVE by testing five different models: co-dominant, dominant, recessive, over dominant and log-additive. Table 2 shows the three SNPs that were significantly associated with higher odds of having a CVE under the selected genetic model. Complete information for all SNPs and models is shown in Supplemental Tables S2-S6. For rs1126616 and rs9138, the over dominant models yielded significant differences, and for rs1126772 the dominant model returned the highest odds ratio and the lowest $p$ value. As the three SNPs are in almost complete linkage disequilibrium (Figure 1), for further analysis we only considered the rs1126616, as the number of missing values was lower in this SNP.

Taking into account the importance of rs1126616, we performed a Kaplan-Meier survival analysis to determine its effect on CVE. Figure 2 shows that patients with homozygote genotypes present a lower incidence of CVE than patients with the heterozygote genotype. The differences between both groups were assessed with a log-rank test, reaching a significant $p$ value of 0.029 . 
Table 2. Selected models of inheritance for the three SPP1 polymorphisms associated with the presence of cardiovascular events.

\begin{tabular}{|c|c|c|c|c|c|c|}
\hline $\operatorname{SNP}(n)$ & Model & Genotype & $\begin{array}{l}\text { NO CVE } n \\
(\%)\end{array}$ & CVE $n(\%)$ & $\begin{array}{c}\text { Odds Ratio } \\
\text { (95\% CI) }\end{array}$ & $\begin{array}{c}p \\
\text { Value }\end{array}$ \\
\hline \multirow{2}{*}{ rs1126616(2815) } & Over & CC-TT & $1512(58)$ & $102(49.5)$ & 1.00 & \multirow{2}{*}{0.019} \\
\hline & dominant & $\mathrm{CT}$ & $1097(42)$ & $104(50.5)$ & $1.41(1.06-1.87)$ * & \\
\hline \multirow{2}{*}{ rs1126772(1613) } & \multirow{2}{*}{ Dominant } & $\mathrm{AA}$ & 903 (59.9) & $49(46.2)$ & 1.00 & \multirow{2}{*}{0.006} \\
\hline & & AG-GG & $604(40.1)$ & $57(53.8)$ & $1.74(1.17-2.58)^{*}$ & \\
\hline \multirow{2}{*}{ rs9138(2815) } & Over & AA-CC & 1549 (59.3) & $106(51.5)$ & 1.00 & \multirow{2}{*}{0.028} \\
\hline & dominant & $\mathrm{AC}$ & 1062 (40.7) & $100(48.5)$ & $1.38(1.04-1.83)$ * & \\
\hline
\end{tabular}

* Significant odds ratio. Odds ratio is referred to dominant homozygote for each model. The $p$ value is for model performance for each individual polymorphism against other possible models (co-dominant, dominant, recessive, over dominant, log-additive). CVE, cardiovascular event; SNP: single nucleotide polymorphisms; $95 \%$ CIs: $95 \%$ confidence intervals; SPP1: Osteopontin gene.

NO CV Events

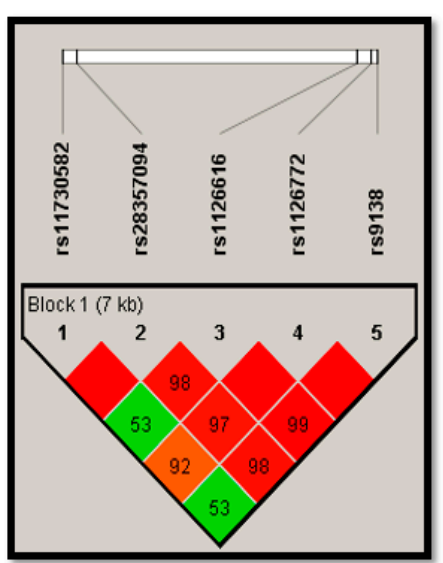

CV Events

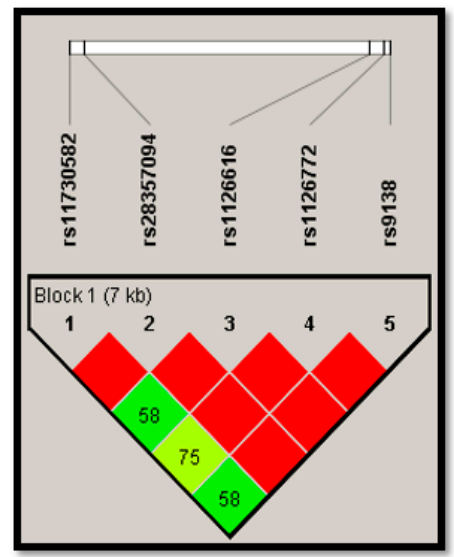

Figure 1. Plots showing linkage disequilibrium (LD) of alleles at different SNPs of SPP1 in chronic kidney disease patients stratified according to the presence of cardiovascular events. SNPs: single nucleotide polymorphisms; SPP1: Osteopontin gene; CV: cardiovascular.

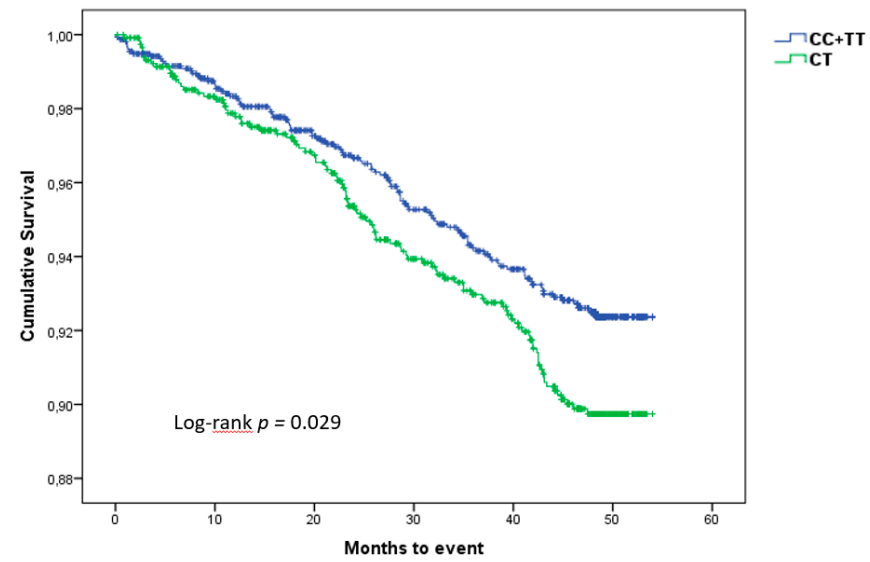

Figure 2. Kaplan-Meier curves showing the difference in the incidence of cardiovascular events according to genotype, during the follow-up period.

When our cohort was analyzed according to the proposed genetic model, significant differences were observed only for the incidence of CVE (Table 3). Notably, OPN levels were almost equal between both groups and were similarly modified by the CKD stage (Figure 3). 
Table 3. Association of SPP1 rs1126616 C > T polymorphism with epidemiological, clinical and biochemical parameters of the cohort.

\begin{tabular}{|c|c|c|c|c|}
\hline \multirow{3}{*}{\multicolumn{2}{|c|}{ Variables }} & GENOTYPES & GENOTYPE & \multirow{3}{*}{$p$ Value } \\
\hline & & $\mathrm{CC}+\mathrm{TT}$ & CT & \\
\hline & & $n=1555$ & $n=1168$ & \\
\hline \multicolumn{2}{|c|}{ Age (years) } & $56.36(12.48)$ & $57.96(12.48)$ & 0.219 \\
\hline \multicolumn{2}{|c|}{ Sex (Female) } & $619(39.8)$ & $457(39.1)$ & 0.719 \\
\hline \multicolumn{2}{|c|}{ Body mass index $\left(\mathrm{kg} / \mathrm{m}^{2}\right)$} & $28.12(5)$ & $28.38(5.1)$ & 0.186 \\
\hline \multicolumn{2}{|c|}{ Smoking (Yes) } & $886(57)$ & $689(59)$ & 0.293 \\
\hline \multicolumn{2}{|c|}{ Diabetes (Yes) } & $357(23)$ & $253(21)$ & 0.442 \\
\hline \multicolumn{2}{|c|}{ Hypertension (Yes) } & $1225(78.8)$ & $953(81.6)$ & 0.069 \\
\hline \multicolumn{2}{|c|}{ Dyslipemia } & $946(60.8)$ & $703(60.2)$ & 0.732 \\
\hline \multicolumn{2}{|c|}{ Systolic blood pressure $(\mathrm{mmHg})$} & $140.99(21.47)$ & $141.17(21.71)$ & 0.823 \\
\hline \multicolumn{2}{|c|}{ Dyastolic blood pressure (mmHg) } & $81.14(11.39)$ & $80.93(11.34)$ & 0.627 \\
\hline \multirow{4}{*}{$\begin{array}{l}\text { Chronic kidney } \\
\text { disease Stage }\end{array}$} & Control & $334(21.5)$ & $205(17.6)$ & \multirow{4}{*}{0.058} \\
\hline & Stage 3 & $485(31.2)$ & $382(32.7)$ & \\
\hline & Stage $4-5$ & $413(26.6)$ & $310(26.5)$ & \\
\hline & Dialysis & $323(20.8)$ & $271(23.2)$ & \\
\hline \multicolumn{2}{|c|}{ Cardiovascular Events } & $100(6.4)$ & 101(8.6) & 0.029 \\
\hline \multicolumn{2}{|c|}{ Any basal plaque (yes) } & 1048(67.4) & $785(67.2)$ & 0.918 \\
\hline \multicolumn{2}{|c|}{ Total Cholesterol (mg/dL) } & $183.71(40,44)$ & $182.66(38.73)$ & 0.5 \\
\hline \multicolumn{2}{|c|}{ HDL Cholesterol (mg/dL) } & $50.45(15.49)$ & $50.12(15.41)$ & 0.606 \\
\hline \multicolumn{2}{|c|}{ LDL Cholesterol (mg/dL) } & $107.32(35.21)$ & $106.42(34.08)$ & 0.534 \\
\hline \multicolumn{2}{|c|}{ Triglycerides (mg/dL) } & $136.58(76.54)$ & $140.85(81.53)$ & 0.17 \\
\hline \multicolumn{2}{|c|}{ C-reactive protein } & $4.33(8.55)$ & $4.34(8.26)$ & 0.964 \\
\hline \multirow{3}{*}{ ACR (mgAlb/gCreat) } & $\mathrm{ACR}<30$ & 239 (34.9) & $168(31.2)$ & \multirow{3}{*}{0.390} \\
\hline & $\mathrm{ACR}=30-300$ & $242(35.3)$ & $201(37.3)$ & \\
\hline & ACR > 300 & $204(29.8)$ & $170(31.5)$ & \\
\hline \multicolumn{2}{|c|}{ Glucose (mg/dL) } & $106.76(39.22)$ & $105.91(34.23)$ & 0.55 \\
\hline \multicolumn{2}{|c|}{ Calcium (mg/dL) } & $9.32(0.58)$ & $9.35(0.55)$ & 0.18 \\
\hline \multicolumn{2}{|c|}{ Phosphate (mg/dL) } & $3.97(1.06)$ & $3.96(1.05)$ & 0.768 \\
\hline \multicolumn{2}{|c|}{ Sodium (mEq/L) } & $140.36(2.97)$ & $140.51(2.98)$ & 0.176 \\
\hline \multicolumn{2}{|c|}{ Potassium (mEq/L) } & $4.75(0.6)$ & $4.74(0.56)$ & 0.642 \\
\hline
\end{tabular}

$p$ value $<0.05$ boldface typed. Qualitative variables are expressed as $\mathrm{n}(\%)$ and quantitative variables as mean (SD). Comparisons between groups performed with Student's $t$ test for quantitative variables, and Chi-squared test for categorical data. HDL, high-density lipoprotein; LDL, low-density lipoprotein; ACR, urine albumin to creatinine ratio; OPN, Osteopontin.

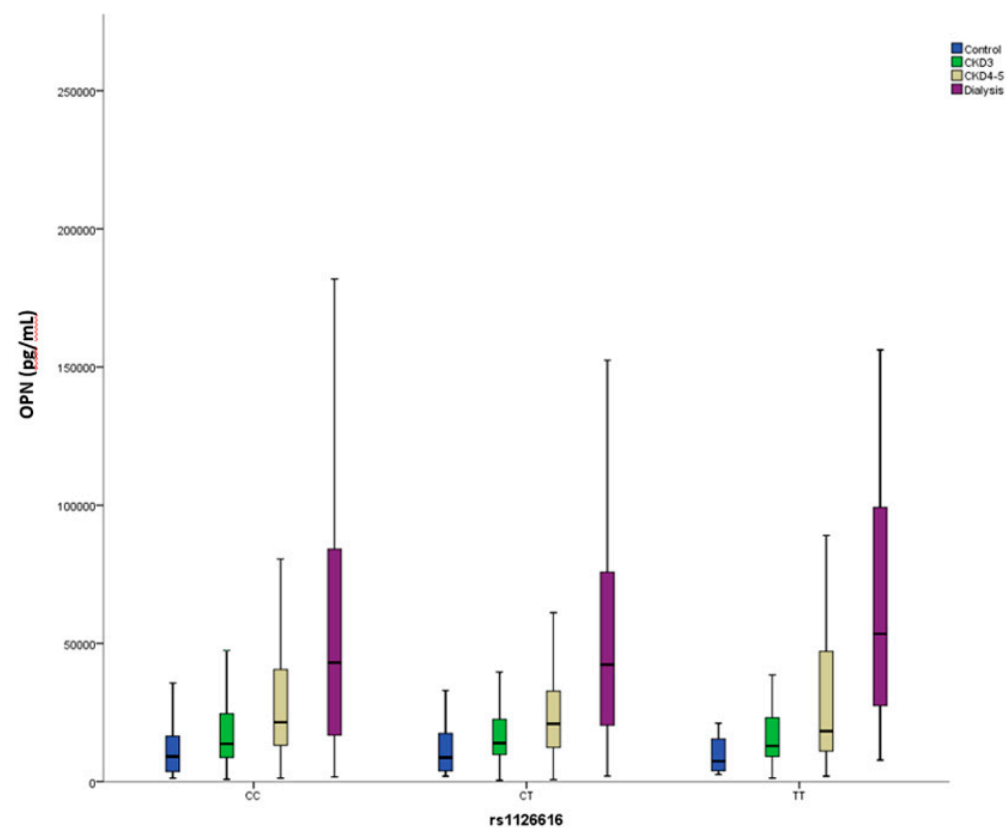

Figure 3. Circulating Osteopontin (OPN) levels stratified according to rs1126616 genotype and chronic kidney disease stage. 
Then we performed a multivariate proportional hazards Cox regression analysis including clinical and biochemical variables theoretically associated with a higher risk of presenting a CVE, together with the rs 1126616 polymorphism. As shown in Table 4, variables with a statistically significant association with CVE were older age, the presence of diabetes and atheromatous plaque, higher levels of phosphate and c-reactive protein, and lower levels of HDL cholesterol and vitamin D. Heterozygosity for the rs1126772 genotype was associated with higher hazards of having a CVE.

Table 4. Cox regression modelling the incidence of CVE including dialysis patients $(n=2093)$.

\begin{tabular}{ccc}
\hline Variables & HR $\mathbf{( 9 5 \% ~ C I )}$ & $p$ Value \\
\hline Age (years) & $1.020(1.003-1.038)$ & 0.024 \\
Diabetes & $1.705(1.23-2.36)$ & 0.001 \\
HDL Cholesterol (mg/dL) & $0.983(0.972-0.995)$ & 0.005 \\
Phosphate $(\mathrm{mg} / \mathrm{dL})$ & $1.387(1.218-1.579)$ & $<0.001$ \\
25(OH) vitamin D $(\mathrm{ng} / \mathrm{mL})$ & $0.95(0.924-0.976)$ & $<0.001$ \\
C-reactive protein & $1.013(1.001-1.024)$ & 0.037 \\
Plaque presence & $2.555(1.461-4.468)$ & 0.001 \\
rs1126616 & $1.462(1.067-2.004)$ & 0.018 \\
\hline
\end{tabular}

Variables that did not reach significance level: Sex, BMI, Smoker, Hypertension, Dyslipemia, Systolic blood pressure (SBP), Diastolic blood pressure (DBP), CKD stage, Total cholesterol, LDL cholesterol, triglycerides, glucose, calcium, and OPN tertile. HR, Hazard Ratio. CI: Confidence Intervals.

Although the previous model was adjusted by CKD stage, we performed a sensitivity analysis eliminating the dialysis patients because they have a higher mortality rate. Thus, in Table 5 we show the Cox regression model further adjusted by proteinuria. The results show that the rs1126616 polymorphism is still significantly associated with the incidence of CVE.

Table 5. Cox regression modelling the incidence of CVE excluding dialysis patients $(n=1021)$.

\begin{tabular}{ccc}
\hline Variables & HR $\mathbf{( 9 5 \% ~ C I ) ~}$ & $p$ Value \\
\hline Diabetes & $1.913(1.196-3.060)$ & 0.007 \\
HDL Cholesterol (mg/dL) & $0.975(0.957-0.994)$ & 0.008 \\
Plaque presence & $2.438(1.265-4.697)$ & 0.008 \\
C-reactive protein & $1.019(1.005-1.034)$ & 0.01 \\
rs1126616 & $1.626(1.026-2.576)$ & 0.039
\end{tabular}

Variables that did not reach significance level: Age, Sex, BMI, Smoker, Hypertension, Dyslipemia, SBP, DBP, CKD stage, Total cholesterol, LDL cholesterol, triglycerides, albumin to creatinine ratio, glucose, calcium, phosphate, 25(OH) vitamin D and OPN tertile. HR: Hazard Ratio; CI: Confidence Intervals.

\section{Discussion}

Cardiovascular events are one of the main complications of CKD patients, in which cardiovascular mortality is the main cause of death [33]. The causes of this excess of cardiovascular complications are not clear, although an increase in atherosclerotic-related problems has been suggested [3,34]. Accelerated atherosclerosis is a clinical feature associated with CKD [35], but the mechanisms involved are not fully understood. Among the metabolic alterations presented by CKD patients that could be involved in the excessive cardiovascular complications, changes in mineral metabolism are suggested to play a role $[2,36,37]$. OPN is a protein that is implicated in calcification, proliferation, and migration of vascular smooth muscle cells, providing a possible link between mineral metabolism and formation of atheroma plaque [38-40].

There is a clear association of OPN protein levels with atherosclerosis [6] and cardiovascular disease [41], and many studies have shown an association of higher OPN levels with CVE in several populations, including the NEFRONA cohort [5,42-44]. In our analysis, in agreement with previous reports, OPN levels increased progressively with the degree of renal function impairment [18], and were higher in patients with CVE. However, after adjustment for traditional risk factors and rs1126616, 
OPN levels were no longer significantly associated with the incidence of CVE. In any case, in the multivariate proportional hazards Cox regression analysis, the higher tertile of OPN almost reached statistical significance (Hazard Ratio: 2.9; $p=0.088$; data not shown) so probably, the relatively low number of events precluded the analysis from having enough potency to show the association of OPN levels with CVE.

Currently, there are few studies analyzing OPN polymorphisms and CVE. The results of the present study demonstrate that rs1126616 polymorphism of the SPP1 gene is independently associated with a higher incidence of CVE in a cohort of CKD patients. A previous study from Brand-Herrmann and colleagues did not find any association of the SPP1 rs1126616 SNP to myocardial or brain infarction [19], but differs from our study in many aspects. The NEFRONA study is a prospective cohort study of mainly CKD patients, and our endpoint (CVE) is a composite containing all cardiovascular events. Norman et al. investigated the association between OPN SNPs and abdominal aortic aneurysm (AAA), and found no significant associations between rs1126616 and AAA or aortic diameter, neither with aortic expansion nor with OPN levels [45]. Again, the fact that their cohort was not composed of CKD patients, and that they only focus on AAA could explain differences between both studies. It is worth noting that none of these studies $[19,45]$ tested different genetic models of inheritance, precluding the identification of the over dominant genotype that arose in our study. Usually genetic disease models follow dominant, recessive, or co-dominant models, but over dominant models have been also described in many studies [46-49].

Apart from CVE, the rs1126616 polymorphism has also been found to be associated with CKD [50], urolithiasis [51], and to the prevalence of lupus nephritis [52]. However, no study has previously shown the effect of the SNP on circulating levels of OPN in patients with different stages of CKD. Previous reports have shown no differences in OPN levels between different genotypes of the SNP [51-53]. Our results agree with the previous literature as the different genotypes do not modify the OPN levels, and more advanced stages of CKD show increased levels of OPN. The rs1126616 is not expected to change either the expression of the gene or the sequence of the protein as the SNP is a synonymous change (p.Ala236=) located at the coding region. In our population, rs1126616 is in almost complete LD with the other two SNPs that, consequently, yielded statistically significant differences in the univariate analysis (rs1126772 and rs9138). These two SNPs are located at the $3^{\prime}$ untranslated region but in our study, and in agreement with previous reports [51-53], the OPN levels did not change according to these genotypes. Therefore, we cannot rule out that the association found between this SNP and the presence of CVE could be due to another functional SNP in LD with the one we studied.

One limitation of our work is the lack of a validation cohort. As a second limitation, previous Genome-Wide Association Studies (GWAS) did not find any association between any of the present polymorphisms and cardiovascular disease [54]. However, this could be due to the very strict limitations applied to $p$ values in those kind of studies. As for strengths of the current work, this is the first time that SPP1 gene polymorphisms have been analyzed in a relatively large CKD population on which OPN levels have been related to phenotype and genotype. Moreover, the many clinical and biochemical data of NEFRONA study allowed us to better adjust and to put into context the effect of the selected SNPs.

In conclusion, the rs $1126616 \mathrm{SNP}$ of the SPP1 gene is independently associated with cardiovascular events in a cohort of CKD patients regardless of OPN levels and thus, if validated, could be used to predict CVE risk in CKD patients.

Supplementary Materials: The following are available online at http://www.mdpi.com/2077-0383/8/5/592/s1, Table S1: HWE equilibrium for the five SPP1 SNPs analyzed. Table S2: Genetic polymorphism of SPP1 rs1126772 A/G in association with CVE in CKD patients. Table S3: Genetic polymorphism of SPP1 rs1126616 C/T in association with CVE in CKD patients. Table S4: Genetic polymorphism of SPP1 rs9138 A/C in association with CVE in CKD patients. Table S5: Genetic polymorphism of SPP1 rs11730582 C/T in association with CVE in CKD patients. Table S6: Genetic polymorphism of SPP1 rs28357094 G/T in association with CVE in CKD patients. 
Author Contributions: Conceptualization, J.M.V., I.R., S.C., R.K.M.; methodology, J.M.V., S.C., R.K.M.; formal analysis J.M.V., R.K.G., S.C.; resources, J.M.V.; data curation, S.C. and J.M.V.; writing-original draft preparation, S.C.; writing-review and editing, S.C., J.M.V., I.R., M.B.-L., M.B.; project administration, J.M.V.; funding acquisition, J.M.V.

Funding: The NEFRONA study was funded by a research grant from AbbVie, FEDER funds and the Instituto de Salud Carlos III RETIC (RD16/0009), FIS PI16/01354, and PI18/00694. I.R. was financially supported by Fundación para el Fomento en Asturias de la Investigación Científica Aplicada y la Tecnología (FICYT).

Acknowledgments: The authors would like to thank the NEFRONA team (Eva Castro, Virtudes María, Teresa Molí, Teresa Vidal, Meritxell Soria) and the Biobank of REDinREN for their invaluable support. The NEFRONA study investigator group is composed by the following: Aladrén Regidor, Ma José. Hospital Comarcal Ernest Lluch (Calatayud); Almirall, Jaume; Ponz, Esther. Corporació Parc Taulí (Barcelona); Arteaga Coloma, Jesús. Hospital de Navarra (Pamplona); Bajo Rubio, Ma Auxiliadora; Díaz, Raquel Raquel Hospital La Paz (Madrid); Belart Rodríguez, Montserrat. Sistemes Renals (Lleida); Gascón, Antonio, Hospital Obispo Polanco (Teruel); Bover Sanjuan, Jordi. Fundació Puigvert. IIB Sant Pau (Barcelona); Bronsoms Artero, Josep. Clínica Girona (Girona); Cabezuelo Romero, Juan B; Muray Cases, Salomé. Hospital Reina Sofía (Murcia); Calviño Varela, Jesús. Hospital Universitario Lucus Augusti (Lugo); Caro Acevedo, Pilar. Clínica Ruber (Madrid); Carreras Bassa, Jordi. Diaverum Baix Llobregat (Barcelona); Cases Amenós, Aleix; Massó Jiménez, Elisabet. Hospital Clínic (Barcelona); Moreno López, Rosario. Hospital de la Defensa (Zaragoza); Cigarrán Guldris, Secundino; López Prieto, Saray. Hospital Da Costa (Lugo); Comas Mongay, Lourdes. Hospital General de Vic (Barcelona); Comerma, Isabel. Hospital General de Manresa (Barcelona); Compte Jové, Ma Teresa, Hospital de la Santa Creu de Jesús (Tarragona); Cuberes Izquierdo, Marta. Hospital Reina Sofía (Navarra); de Álvaro, Fernando; Hevia Ojanguren, Covadonga. Hospital Infanta Sofía (Madrid); de Arriba de la Fuente, Gabriel. Hospital Universitario de Guadalajara (Guadalajara); del Pino y Pino, Ma Dolores. Complejo Hospitalario Torrecardenas de Almeria (Almería); Diaz-Tejeiro Izquierdo, Rafael; Ahijado Hormigos, Francisco Hospital Virgen de la Salud (Toledo); Dotori, Marta. USP Marbella (Málaga); Duarte, Verónica. Hospital de Terrassa (Barcelona); Estupiñan Torres, Sara. Hospital Universitario de Canarias (Santa Cruz de Tenerife); Fernández Reyes, Ma José. Hospital de Segovia (Segovia); Fernández Rodríguez, Ma Loreto. Hospital Príncipe de Asturias (Madrid); Fernández, Guillermina. Clínica Santa Isabel (Seville); Galán Serrano, Antonio. Hospital General Universitari de València (Valencia); García Cantón, Cesar. Hospital Universitario Insular de Gran Canaria (Las Palmas); García Herrera, Antonio L. Hospital Universitario Puerto Real (Cádiz); García Mena, Mercedes. Hospital San Juan de Dios (Zaragoza); Gil Sacaluga, Luis; Aguilar, Maria. Hospital Virgen del Rocío (Seville); Górriz, José Luis. Hospital Universitario Doctor Peset (Valencia); Huarte Loza, Emma. Hospital San Pedro (Logroño); Lerma, José Luis. Hospital Universitario de Salamanca (Salamanca); Liebana Cañada, Antonio. Hospital de Jaén (Jaén); Marín Álvarez, Jesús Pedro. Hospital San Pedro de Alcántara (Cáceres); Martín Alemany, Nàdia. Hospital Universitari Dr. Josep Trueta (Girona); Martín García, Jesús. Hospital Nuestra Señora de Sonsoles (Ávila); Martínez Castelao, Alberto. Hospital Universitari de Bellvitge (Barcelona); Martínez Villaescusa, María. Complejo Hospitalario Universitario de Albacete (Albacete); Martínez, Isabel. Hospital Galdakao (Bilbao); Moina Eguren, Iñigo. Hospital Basurto (Bilbao); Moreno Los Huertos, Silvia. Hospital Santa Bárbara (Soria); Mouzo Mirco, Ricardo. Hospital El Bierzo, Ponferrada (León); Munar Vila, Antonia. Hospital Universitari Son Espases (Palma de Mallorca); Muñoz Díaz, Ana Beatriz. Hospital Vithas Nisa Virgen del Consuelo (Valencia); Navarro González, Juan F. Hospital Universitario Nuestra Señora de Candelaria (Santa Cruz de Tenerife); Nieto, Javier; Carreño, Agustín. Hospital General Universitario de Ciudad Real (Ciudad Real); Novoa Fernández, Enrique. Complexo Hospitalario de Ourense (Ourense); Ortiz, Alberto; Fernandez, Beatriz. IIS-Fundación Jiménez Díaz (Madrid); Paraíso, Vicente. Hospital Universitario del Henares (Madrid); Pérez Fontán, Miguel. Complejo Hospitalario Universitario A Coruña (A Coruña); Peris Domingo, Ana. Hospital Francesc de Borja (Valencia); Piñera Haces, Celestino. Hospital Universitario Marqués de Valdecilla (Santander); Prados Garrido, Ma Dolores. Hospital Universitario San Cecilio (Granada); Prieto Velasco, Mario. Hospital de León (León); Puig Marí, Carmina. Hospital d'Igualada (Barcelona); Rivera Gorrín, Maite. Hospital Universitario Ramón y Cajal (Madrid); Rubio, Esther. Hospital Puerta de Hierro-Majadahonda (Madrid); Ruiz, Pilar. Hospital de Sant Joan Despí Moisès Broggi (Barcelona); Salgueira Lazo, Mercedes; Martínez Puerto, Ana Isabel. Hospital Universitario Virgen Macarena (Seville); Sánchez Tomero, José Antonio. Hospital Universitario de la Princesa (Madrid); Sánchez, José Emilio. Hospital Universitario Central de Asturias (Oviedo); Sans Lorman, Ramon. Hospital de Figueres (Girona); Saracho, Ramon. Hospital de Santiago (Vitoria); Sarrias, Maria; Serón, Daniel. Hospital Universitari Vall d'Hebron (Barcelona); Soler, María José; Barrios, Clara. Hospital del Mar (Barcelona); Sousa, Fernando. Hospital Rio Carrión (Palencia); Toran, Daniel. Hospital General de Jerez (Cadiz); Tornero Molina, Fernando. Hospital Universitario Del Sureste (Arganda del Rey); Usón Carrasco, José Javier. Hospital Virgen de la Luz (Cuenca); Valera Cortes, Ildefonso. Hospital Virgen de la Victoria (Málaga); Vilaprinyo del Perugia, Ma Merce. Institut Catala d'Urologia i Nefrologia (Barcelona); Virto Ruiz, Rafael C. Hospital San Jorge (Huesca); Vicente Pallarés Carratalá Clinica MEDEFIS (Vila-real. Castellón), Carlos Santos Altozano CS Azuqueca de Henares (Guadalajara); Miguel Artigao Ródenas CS Zona III (Albacete); Inés Gil Gil Área Básica Sanitaria de Arán. CAP Viella (Lleida); Francisco Adan Gil CS Alfaro (La Rioja); Emilio García Criado Centro de Salud del Carpio (Córdoba); Rafael Durá Belinchón CS Godella (Valencia); Jose Ma Fernández Toro CS Zona Centro (Cáceres); Juan Antonio Divisón Garrote Centro de Salud de Casas Ibáñez. Consultorio de Fuentealbilla (Albacete).

Conflicts of Interest: The authors declare no conflict of interest. 


\section{References}

1. Chronic Kidney Disease Prognosis Consortium. Association of estimated glomerular filtration rate and albuminuria with all-cause and cardiovascular mortality in general population cohorts: A collaborative meta-analysis. Lancet 2010, 375, 2073-2081. [CrossRef]

2. Betriu, A.; Martinez-Alonso, M.; Arcidiacono, M.V.; Cannata-Andía, J.B.; Pascual, J.; Valdivielso, J.M.; Fernández, E. Prevalence of subclinical atheromatosis and associated risk factors in chronic kidney disease: The NEFRONA study. Nephrol. Dial. Transplant. 2014, 29, 1415-1422. [CrossRef]

3. Valdivielso, J.M.; Betriu, À.; Martínez-Alonso, M.; Arroyo, D.; Bermudez-Lopez, M.; Fernandez, E. for the NEFRONA investigators Factors predicting cardiovascular events in chronic kidney disease patients. Role of subclinical atheromatosis extent assessed by vascular ultrasound. PLoS ONE 2017, 12, e0186665. [CrossRef]

4. D'Marco, L.; Bellasi, A.; Raggi, P. Cardiovascular Biomarkers in Chronic Kidney Disease: State of Current Research and Clinical Applicability. Dis. Markers 2015, 2015, 586569. [CrossRef]

5. Bozic, M.; Méndez-Barbero, N.; Gutiérrez-Muñoz, C.; Betriu, À.; Egido, J.; Fernandez, E.; Martin-Ventura, J.L.; Valdivielso, J.M.; Blanco-Colio, L.M. Combination of biomarkers of vascular calcification and sTWEAK to predict cardiovascular events in chronic kidney disease. Atherosclerosis 2018, 270, 13-20. [CrossRef]

6. Cho, H.-J.; Cho, H.-J.; Kim, H.-S. Osteopontin: A multifunctional protein at the crossroads of inflammation, atherosclerosis, and vascular calcification. Atheroscler. Rep. 2009, 11, 206-213. [CrossRef]

7. Hirota, S.; Imakita, M.; Kohri, K.; Ito, A.; Morii, E.; Adachi, S.; Kim, H.M.; Kitamura, Y.; Yutani, C.; Nomura, S. Expression of osteopontin messenger RNA by macrophages in atherosclerotic plaques. A possible association with calcification. Am. J. Pathol. 1993, 143, 1003-1008.

8. O’Brien, E.R.; Garvin, M.R.; Stewart, D.K.; Hinohara, T.; Simpson, J.B.; Schwartz, S.M.; Giachelli, C.M. Osteopontin is synthesized by macrophage, smooth muscle, and endothelial cells in primary and restenotic human coronary atherosclerotic plaques. Arter. Thromb. A J. Vasc. Boil. 1994, 14, 1648-1656. [CrossRef]

9. Ikeda, T.; Shirasawa, T.; Esaki, Y.; Yoshiki, S.; Hirokawa, K. Osteopontin mRNA is expressed by smooth muscle-derived foam cells in human atherosclerotic lesions of the aorta. J. Clin. Investig. 1993, 92, $2814-2820$. [CrossRef]

10. Isoda, K.; Nishikawa, K.; Kamezawa, Y.; Yoshida, M.; Kusuhara, M.; Moroi, M.; Tada, N.; Ohsuzu, F. Osteopontin Plays an Important Role in the Development of Medial Thickening and Neointimal Formation. Circ. Res. 2002, 91, 77-82. [CrossRef] [PubMed]

11. Matsui, Y.; Rittling, S.R.; Okamoto, H.; Inobe, M.; Jia, N.; Shimizu, T.; Akino, M.; Sugawara, T.; Morimoto, J.; Kimura, C.; et al. Osteopontin Deficiency Attenuates Atherosclerosis in Female Apolipoprotein E-Deficient Mice. Arter. Thromb. Vasc. Boil. 2003, 23, 1029-1034. [CrossRef]

12. Ohmori, R.; Momiyama, Y.; Taniguchi, H.; Takahashi, R.; Kusuhara, M.; Nakamura, H.; Ohsuzu, F. Plasma osteopontin levels are associated with the presence and extent of coronary artery disease. Atherosclerosis 2003, 170, 333-337. [CrossRef]

13. Momiyama, Y.; Ohmori, R.; Fayad, Z.A.; Kihara, T.; Tanaka, N.; Kato, R.; Taniguchi, H.; Nagata, M.; Nakamura, H.; Ohsuzu, F. Associations between plasma osteopontin levels and the severities of coronary and aortic atherosclerosis. Atherosclerosis 2010, 210, 668-670. [CrossRef]

14. Kurata, M.; Okura, T.; Watanabe, S.; Fukuoka, T.; Higaki, J. Osteopontin and carotid atherosclerosis in patients with essential hypertension. Clin. Sci. 2006, 111, 319-324. [CrossRef]

15. Mazzone, A.; Parri, M.S.; Giannessi, D.; Ravani, M.; Vaghetti, M.; Altieri, P.; Casalino, L.; Maltinti, M.; Balbi, M.; et al. Osteopontin plasma levels and accelerated atherosclerosis in patients with CAD undergoing PCI: A prospective clinical study. Coron Artery Dis. 2011, 22, 179-187. [CrossRef]

16. Liaw, L.; Lombardi, D.M.; Almeida, M.M.; Schwartz, S.M.; Deblois, D.; Giachelli, C.M. Neutralizing Antibodies Directed Against Osteopontin Inhibit Rat Carotid Neointimal Thickening After Endothelial Denudation. Arter. Thromb. Vasc. Boil. 1997, 17, 188-193. [CrossRef]

17. Wolak, T. Osteopontin-A multi-modal marker and mediator in atherosclerotic vascular disease. Atherosclerosis 2014, 236, 327-337. [CrossRef]

18. Lorenzen, J.; Krämer, R.; Kliem, V.; Bode-Boeger, S.M.; Veldink, H.; Haller, H.; Fliser, D.; Kielstein, J.T. Circulating levels of osteopontin are closely related to glomerular filtration rate and cardiovascular risk markers in patients with chronic kidney disease. Eur. J. Clin. Investig. 2010, 40, 294-300. [CrossRef] 
19. Schmidt-Petersen, K.; Brand, E.; Telgmann, R.; Nicaud, V.; Hagedorn, C.; Labreuche, J.; Dördelmann, C.; Elbaz, A.; Gautier-Bertrand, M.; Fischer, J.W.; et al. Osteopontin gene variation and cardio/cerebrovascular disease phenotypes. Atherosclerosis 2009, 206, 209-215. [CrossRef]

20. De las Fuentes, L.; Gu, C.C.; Mathews, S.J.; Reagan, J.L.; Ruthmann, N.P.; Waggoner, A.D.; Lai, C.-F.; Towler, D.A.; Dávila-Román, V.G. Osteopontin promoter polymorphism is associated with increased carotid intima-media thickness. J. Am. Soc. Echocardiogr. 2008, 21, 954-960. [CrossRef]

21. Brenner, D.; Labreuche, J.; Touboul, P.-J.; Schmidt-Petersen, K.; Poirier, O.; Perret, C.; Schönfelder, J.; Combadière, C.; Lathrop, M.; Cambien, M.; et al. Cytokine Polymorphisms Associated With Carotid Intima-Media Thickness in Stroke Patients. Stroke 2006, 37, 1691-1696. [CrossRef]

22. Taylor, B.C.; Schreiner, P.J.; Doherty, T.M.; Fornage, M.; Carr, J.J.; Sidney, S.; Carr, J. Matrix Gla protein and osteopontin genetic associations with coronary artery calcification and bone density: The CARDIA study. Hum. Genet. 2005, 116, 525-528. [CrossRef] [PubMed]

23. Pleskovič, A.; Šantl, M.L.; Cokan, A.V.; Makuc, J.; Nikolajević, J.S.; Petrovič, D. Phosphoprotein 1 (osteopontin) gene (rs4754) affects markers of subclinical atherosclerosis in patients with type 2 diabetes mellitus. Int. Angiol. J. Int. Union Angiol. 2018, 37, 64-70.

24. Junyent, M.; Martínez, M.; Borrás, M.; Bertriu, A.; Coll, B.; Craver, L.; Marco, M.P.; Sarró, F.; Valdivielso, J.M.; Fernández, E. Usefulness of imaging techniques and novel biomarkers in the prediction of cardiovascular risk in patients with chronic kidney disease in Spain: The NEFRONA project. Nefrología 2010, 30, 119-126.

25. Junyent, M.; Martínez, M.; Borràs, M.; Coll, B.; Valdivielso, J.M.; Vidal, T.; Sarro, F.; Roig, J.; Craver, L.; Fernández, E.; et al. Predicting cardiovascular disease morbidity and mortality in chronic kidney disease in Spain. The rationale and design of NEFRONA: A prospective, multicenter, observational cohort study. BMC Nephrol. 2010, 11, 14. [CrossRef]

26. Levey, A.S.; Bosch, J.P.; Lewis, J.B.; Rogers, N.; Greene, T.; Roth, D. A More Accurate Method to Estimate Glomerular Filtration Rate from Serum Creatinine: A New Prediction Equation. Ann. Intern. Med. 1999, 130, 461-470. [CrossRef] [PubMed]

27. Stevens, L.A.; Coresh, J.; Greene, T.; Levey, A.S. Assessing Kidney Function-Measured and Estimated Glomerular Filtration Rate. New Engl. J. Med. 2006, 354, 2473-2483. [CrossRef]

28. Coll, B.; Betriu, A.; Martinez-Alonso, M.; Borras, M.; Craver, L.; Amoedo, M.L.; Marco, M.A.P.; Sarro, F.; Junyent, M.; Valdivielso, J.M.; et al. Cardiovascular risk factors underestimate atherosclerotic burden in chronic kidney disease: Usefulness of non-invasive tests in cardiovascular assessment. Nephrol. Dial. Transplant. 2010, 25, 3017-3025. [CrossRef] [PubMed]

29. Calleros-Basilio, L.; Cortés, M.A.; García-Jerez, A.; Luengo-Rodríguez, A.; Orozco-Agudo, A.; Valdivielso, J.M.; Rodríguez-Puyol, D.; Rodríguez-Puyol, M. Quality Assurance of Samples and Processes in the Spanish Renal Research Network (REDinREN) Biobank. Biopreserv. Biobank. 2016, 14, 499-510. [CrossRef]

30. Solé, X.; Guinó, E.; Valls, J.; Iniesta, R.; Moreno, V. SNPStats: A web tool for the analysis of association studies. Bioinformatics 2006, 22, 1928-1929. [CrossRef]

31. Barrett, J.C.; Fry, B.; Maller, J.D.M.J.; Daly, M.J. Haploview: Analysis and visualization of LD and haplotype maps. Bioinformatics 2005, 21, 263-265. [CrossRef]

32. Cunningham, F.; Achuthan, P.; Akanni, W.; Allen, J.; Amode, M.R.; Armean, I.M.; Bennett, R.; Bhai, J.; Billis, K.; Boddu, S.; et al. Ensembl 2019. Nucleic Acids Res. 2019, 47, D745-D751. [CrossRef] [PubMed]

33. Go, A.; Chertow, G.; Fan, D.; McCulloch, C.; Hsu, C. Chronic kidney disease and the risks of death, cardiovascular events, and hospitalization. ACC J. 2004, 13, 13.

34. Thompson, S.; James, M.; Wiebe, N.; Hemmelgarn, B.; Manns, B.; Klarenbach, S.; Tonelli, M.; Network, F.T.A.K.D. Cause of Death in Patients with Reduced Kidney Function. J. Am. Soc. Nephrol. 2015, 26, 2504-2511. [CrossRef]

35. Gracia, M.; Betriu, À.; Martínez-Alonso, M.; Arroyo, D.; Abajo, M.; Fernández, E.; Valdivielso, J.M. Predictors of Subclinical Atheromatosis Progression over 2 Years in Patients with Different Stages of CKD. Clin. J. Am. Soc. Nephrol. 2016, 11, 287-296. [CrossRef]

36. Abajo, M.; Betriu, À.; Arroyo, D.; Gracia, M.; Del Pino, M.D.; Martínez, I.; Valdivielso, J.M.; Fernández, E. Mineral metabolism factors predict accelerated progression of common carotid intima-media thickness in chronic kidney disease: The NEFRONA study. Nephrol. Dial. Transplant. 2017, 32, 1882-1891. [CrossRef]

37. Martín, M.; Valls, J.; Betriu, A.; Fernández, E.; Valdivielso, J.M. Association of serum phosphorus with subclinical atherosclerosis in chronic kidney disease. Sex makes a difference. Atherosclerosis. 2015, 241, 264-270. 
38. Lee, S.J.; Baek, S.E.; Jang, M.A.; Kim, C.D. Osteopontin plays a key role in vascular smooth muscle cell proliferation via EGFR-mediated activation of AP-1 and C/EBP $\beta$ pathways. Pharmacol. Res. 2016, 108, 1-8. [CrossRef]

39. Li, J.-J.; Han, M.; Wen, J.-K.; Li, A.-Y. Osteopontin stimulates vascular smooth muscle cell migration by inducing FAK phosphorylation and ILK dephosphorylation. Biochem. Biophys. Commun. 2007, 356, 13-19. [CrossRef]

40. Scatena, M.; Liaw, L.; Giachelli, C.M. Osteopontin: A multifunctional molecule regulating chronic inflammation and vascular disease. Arterioscler. Thromb. Vasc. Biol. 2007, 27, 2302-2309. [CrossRef]

41. Singh, M. Osteopontin: A novel inflammatory mediator of cardiovascular disease. Front. Biosci. 2007, 12, 214. [CrossRef] [PubMed]

42. Gordin, D.; Panduru, N.M.; Thomas, M.C.; Bjerre, M.; Soro-Paavonen, A.; Tolonen, N.; Sandholm, N.; Flyvbjerg, A.; Harjutsalo, V.; Forsblom, C.; et al. Osteopontin Is a Strong Predictor of Incipient Diabetic Nephropathy, Cardiovascular Disease, and All-Cause Mortality in Patients with Type 1 Diabetes. Diabetes Care 2014, 37, 2593-2600. [CrossRef]

43. Abdalrhim, A.D.; Marroush, T.S.; Austin, E.E.; Gersh, B.J.; Solak, N.; Rizvi, S.A.; Bailey, K.R.; Kullo, I.J. Plasma Osteopontin Levels and Adverse Cardiovascular Outcomes in the PEACE Trial. PLoS ONE 2016, 11, e0156965. [CrossRef] [PubMed]

44. Carbone, F.; Rigamonti, F.; Burger, F.; Roth, A.; Bertolotto, M.; Spinella, G.; Pane, B.; Palombo, D.; Pende, A.; Bonaventura, A.; et al. Serum levels of osteopontin predict major adverse cardiovascular events in patients with severe carotid artery stenosis. Int. J. Cardiol. 2018, 255, 195-199. [CrossRef] [PubMed]

45. Golledge, J.; Muller, J.; Shephard, N.; Clancy, P.; Smallwood, L.; Moran, C.; Dear, A.E.; Palmer, L.J.; Norman, P.E. Association Between Osteopontin and Human Abdominal Aortic Aneurysm. Arter. Thromb. Vasc. Boil. 2007, 27, 655-660. [CrossRef] [PubMed]

46. Wang, Z.; Diao, J.; Yue, X.; Zhong, J. Effects of ADIPOQ polymorphisms on individual susceptibility to coronary artery disease: A meta-analysis. Adipocyte 2019. [CrossRef] [PubMed]

47. Hashemi, M.; Moazeni-Roodi, A.; Ghavami, S. Association between CASP3 polymorphisms and overall cancer risk: A meta-analysis of case-control studies. J. Cell. Biochem. 2018, 120, 7199-7210. [CrossRef] [PubMed]

48. Zeng, Y.F.; Sang, J. Five zinc finger protein 350 single nucleotide polymorphisms and the risks of breast cancer: A meta-analysis. Oncotarget 2017, 8, 107273-107282. [CrossRef]

49. Alcaraz-Quiles, J.; Titos, E.; Casulleras, M.; Pavesi, M.; López-Vicario, C.; Rius, B.; Lopategi, A.; de Gottardi, A.; Graziadei, I.; Gronbaek, H.; et al. Polymorphisms in the IL-1 gene cluster influence systemic inflammation in patients at risk for acute-on-chronic liver failure. Hepatology 2017, 65, 202-216. [CrossRef]

50. Valls, J.; Cambray, S.; Pérez-Guallar, C.; Bozic, M.; Bermúdez-López, M.; Fernández, E.; Betriu, À.; Rodríguez, I.; Valdivielso, J.M. Association of Candidate Gene Polymorphisms with Chronic Kidney Disease: Results of a Case-Control Analysis in the Nefrona Cohort. Front. Genet. 2019, 10, 118. [CrossRef]

51. Li, X.; Liu, K.; Pan, Y.; Zhang, J.; Lv, Q.; Hua, L.; Wang, Z.; Li, J.; Yin, C. Roles of Osteopontin Gene Polymorphism (rs1126616), Osteopontin Levels in Urine and Serum, and the Risk of Urolithiasis: A Meta-Analysis. BioMed Int. 2015, 2015, 1-9. [CrossRef] [PubMed]

52. Salimi, S.; Noora, M.; Nabizadeh, S.; Rezaei, M.; Shahraki,H.; Milad, M.-K.; Naghavi, A.; Farajian-Mashhadi, F.; Zakeri, Z.; Sandoughi, M. Association of the osteopontin rs1126616 polymorphism and a higher serum osteopontin level with lupus nephritis. Biomed. Rep. 2016, 4, 355-360. [CrossRef] [PubMed]

53. Lavi, H.; Assayag, M.; Schwartz, A.; Arish, N.; Fridlender, Z.G.; Berkman, N. The association between osteopontin gene polymorphisms, osteopontin expression and sarcoidosis. PLoS ONE 2017, 12, e0171945. [CrossRef] [PubMed]

54. MacArthur, J.; Bowler, E.; Cerezo, M.; Gil, L.; Hall, P.; Hastings, E.; Junkins, H.; McMahon, A.; Milano, A.; Morales, J.; et al. The new NHGRI-EBI Catalog of published genome-wide association studies (GWAS Catalog). Nucleic Acids Res. 2017, 45, D896-D901. [CrossRef]

(C) 2019 by the authors. Licensee MDPI, Basel, Switzerland. This article is an open access article distributed under the terms and conditions of the Creative Commons Attribution (CC BY) license (http://creativecommons.org/licenses/by/4.0/). 